\title{
Patterns of Raised Blood Pressure in Vietnam: Findings from the WHO STEPS Survey 2015
}

\author{
Van Minh Hoang $\mathbb{D}^{1},{ }^{1}$ Quoc Bao Tran, ${ }^{2}$ Thi Hoang Lan Vu ${ }^{1},{ }^{1}$ Thi Kim Ngan Nguyen (D), \\ Bao Giang Kim, ${ }^{3}$ Quynh Nga Pham, ${ }^{4}$ Tuan Lam Nguyen, ${ }^{4}$ Duc Truong Lai $\left(\mathbb{D},{ }^{4}\right.$ \\ Jun Nakagawa, ${ }^{4}$ Hai-Rim Shin, ${ }^{5}$ Warrick Junsuk Kim, ${ }^{5}$ Leanne Riley, ${ }^{6}$ \\ Christina Wadhwani, ${ }^{7}$ Dinh Bac Truong, ${ }^{2}$ and Dac Phu Tran ${ }^{2}$ \\ ${ }^{1}$ Hanoi University of Public Health (HUPH), Hanoi, Vietnam \\ ${ }^{2}$ Division of Non-Communicable Diseases, General Department of Preventive Medicine, Ministry of Health, Hanoi, Vietnam \\ ${ }^{3}$ Hanoi Medical University, Hanoi, Vietnam \\ ${ }^{4}$ World Health Organization Country Office, Hanoi, Vietnam \\ ${ }^{5}$ World Health Organization, Regional Office for the Western Pacific, Manila, Philippines \\ ${ }^{6}$ World Health Organization, HQ Office, Geneva, Switzerland \\ ${ }^{7}$ University of Basel, Basel, Switzerland
}

Correspondence should be addressed to Thi Kim Ngan Nguyen; ntkn@huph.edu.vn

Received 18 March 2019; Revised 15 September 2019; Accepted 6 November 2019; Published 1 December 2019

Academic Editor: Tomohiro Katsuya

Copyright (c) 2019 Van Minh Hoang et al. This is an open access article distributed under the Creative Commons Attribution License, which permits unrestricted use, distribution, and reproduction in any medium, provided the original work is properly cited.

\begin{abstract}
This study aims to describe the prevalence of raised blood pressure and the situation of management for raised blood pressure among the adult population in Vietnam. It also aims to examine the association between diversified socioeconomic and behavioral factors of raised blood pressure and awareness of raised blood pressure. Data were obtained from the STEPS survey conducted in Vietnam in 2015. Survey sample was nationally representative with a total of 3,856 people aged 18-69 years old. The study outcomes included raised blood pressure and awareness of and control of raised blood pressure. Multiple logistic regression was used to examine the association of socioeconomic and behavior risk factors with the outcome variables. The overall prevalence of raised blood pressure in Vietnam in 2015 was 18.9\% (95\% CI: 17.4\%-20.6\%). The prevalence of raised blood pressure was higher among men. Significantly correlated factors with raised blood pressure were age, sex, body mass index, and diabetes status. Levels of awareness of raised blood pressure were higher among the older age group and overweight people and lower among ethnic minority groups. Raised blood pressure in Vietnam is a serious problem due to its magnitude and the unacceptably high unawareness rate in the population. Public health actions dealing with the problems of raised blood pressure are urgent, while taking into account its relationship with sex and socioeconomic status. It is clear that the interventions should address all people in society, with a focus on disadvantaged groups which are the rural and ethnic minority peoples.
\end{abstract}

\section{Introduction}

High blood pressure (or raised blood pressure), known as a "silent killer," is associated with approximately 9.4 million cases of death a year worldwide [1]. Traditionally, raised blood pressure has been estimated based on the definition of systolic blood pressure $\geq 140 \mathrm{mmHg}$ and/or diastolic $\geq 90 \mathrm{mmHg}$ or currently on medication for high blood pressure [2]. In 2013, the World Health Assembly adopted the global noncommunicable diseases (NCD) monitoring framework in which raised blood pressure is defined as systolic blood pressure $\geq 140 \mathrm{mmHg}$ and/or diastolic $\geq 90 \mathrm{mmHg}$, regardless of whether the individual is on medication for high blood pressure. With this definition, the global prevalence of raised blood pressure in adults aged 18 years and above was around $22 \%$ in 2014 [3]. The advantage 
of the new definition is that each country will be able to reduce the prevalence of raised blood pressure if it can effectively control blood pressure in hypertensive patients. However, this indicator will not tell the size of the problem which includes those who are currently on medication. Therefore, in this paper, we will use the traditional definition of raised blood pressure which will include those who are currently on medication. The increase in prevalence of raised blood pressure is associated with population ageing and the rise in occurrence of behavioral risk factors, such as tobacco use, unhealthy diet, harmful use of alcohol, physical inactivity, overweight, and persistent stress [4]. Many people with high blood pressure in low-and middle-income countries are not aware of their hypertensive status, and lack access to treatment, and management services [4].

Vietnam has been undergoing health transition where populations are suffering from a "double burden" of communicable diseases and NCDs, including raised blood pressure $[5,6]$. There were a few surveys aiming to access the level of raised blood pressure in Vietnam but they were only covering a small number of provinces, with different sampling methods and using different age ranges. For example, a cross-sectional survey with a sample from eight provinces and cities in Vietnam were conducted during 2002-2008 by the Vietnam National Heart Institute, covering the age range of 25 and above [7]. The World Health Organization (WHO) STEPwise approach to Surveillance (STEPS) of chronic disease risk factors in Vietnam 2009-2010 was taken among those aged 25-64, also from 8 provinces [8].

In 2015, for the first time, a WHO STEPS survey was conducted in a nationally representative sample which provided a good opportunity for Vietnam to establish a national prevalence and to explore factors related to raised blood pressure and its control.

Therefore, we aim to describe the prevalence of raised blood pressure and the situation of awareness and control of raised blood pressure among the adult population in Vietnam. We also aim to examine the association between diversified socioeconomic and behavioral factors of raised blood pressure and awareness of raised blood pressure.

\section{Methods}

2.1. Data Source. Data for this paper were obtained from the WHO STEPS survey conducted in Vietnam in 2015. This was a cross-sectional survey applying the standard methods and tools provided by the World Health Organization [9]. The survey was conducted in a sample from all 63 provinces/ cities of Vietnam between June and October 2015. Survey participants were Vietnamese people aged 18-69 years old who were residing in Vietnam at the time conducting the survey. Exclusion criteria included (1) those who were not residing permanently in Vietnam; (2) patients who were admitted at a health facility at the time of the survey; and (3) people with mental health problems who cannot respond to the survey questions.

Sample size calculation was done using the sample calculator for STEPS provided by WHO [9]. A total of 3,856 people aged 18-69 years were selected for the survey. The two-stage random systematic sampling method was used. In the first stage, primary sampling units (PSUs) which included a cluster of households was identified. In the second stage, random selection of individual households within each cluster was done. In each household, one person between the ages of 18 and 69 was selected using the Kish Grid method. The sampling frame for the survey was developed by the General Statistics Office of Viet Nam (GSO) based on the master sampling frame used in the Population and Housing Census 2009 and updated with data of 2014. The first stage of the survey was conducted in the household using a questionnaire. The second (physical measurement) and third stages (biochemical tests) were conducted in a commune health station after the interview was conducted at the households.

2.2. Dependent Variables. Raised blood pressure was defined as an average (based on STEPS rule) systolic blood pressure (SBP) $\geq 140 \mathrm{mmHg}$ and/or average diastolic blood pressure (DBP) $\geq 90 \mathrm{mmHg}$ and/or self-reported current medication for high blood pressure in the previous two weeks. Digital automatic devices recommended by the WHO (BOSO device) were used for blood pressure measurements.

Management of raised blood pressure was measured by three indicators: awareness of high blood pressure (participants with raised blood pressure who were aware of their condition), treatment of high blood pressure (participants with raised blood pressure who reported current use of antihypertensive medications), and control of high blood pressure (participants who are currently on medication for raised blood pressure and have a blood pressure below 140/ $90 \mathrm{mmHg})$.

2.3. Independent Variables. Demographic variables were included, such as (1) sex (male and female); (2) age groups (i.e., 18-29, 30-49, and 50-69); (3) educational level (primary or less, secondary, and university/college); (4) occupation (senior officials and professionals, elementary occupations, and others); (5) residence (urban and rural); and (6) economic status of household, measured based on an asset-based wealth index lower income (two poorest quintiles), middle income (third and fourth quintiles), and higher income (fifth quintile) [10]. Behavioral risk factors for NCDs were also examined, including (1) smoking status (smoker and nonsmoker), (2) drinking status: drinker (consumed at least one standard drink of alcohol in the past 30 days) and nondrinker, and (3) overweight: people had body mass index (BMI) equal to or greater than 25, and non-overweight: BMI $<25$.

2.4. Data Analysis. Descriptive analysis was used to estimate prevalence, and multiple logistic regression was used to model the associations between outcomes variables and sociodemographic factors. Data were analyzed using Epi Info 3.54 and Stata 13 software. Because we used two-stage sampling, the sampling probability is calculated separately 
TABLE 1: Prevalence of hypertension by sociodemographic factors and NCD risk factors, Vietnam 2015.

\begin{tabular}{|c|c|c|c|c|}
\hline & Number (\%) & Hypertensive & Prevalence & $95 \% \mathrm{CI}$ \\
\hline Overall & 3080 & 673 & 18.9 & $17.4-20.6$ \\
\hline \multicolumn{5}{|l|}{ Sex } \\
\hline Men & $1320(49.5)$ & 365 & 23.1 & $20.4-26.0$ \\
\hline Women & $1760(50.5)$ & 308 & 14.9 & $13.1-16.8$ \\
\hline \multicolumn{5}{|l|}{ Age group } \\
\hline $18-29$ & $489(32.4)$ & 47 & 5.4 & $3.1-7.7$ \\
\hline $30-49$ & $1500(43.6)$ & 196 & 7.3 & $14.9-19.7$ \\
\hline $50-69$ & $1091(24.0)$ & 430 & 40.2 & $36.5-43.8$ \\
\hline \multicolumn{5}{|l|}{ Residence } \\
\hline Urban & $1380(34.9)$ & 310 & 18.4 & $16.3-20.8$ \\
\hline Rural & $1700(65.1)$ & 362 & 19.3 & $17.2-21.5$ \\
\hline \multicolumn{5}{|l|}{ Ethnicity } \\
\hline Kinh & $2514(80.2)$ & 578 & 19.8 & $18.0-21.7$ \\
\hline Others & $566(19.8)$ & 95 & 15.5 & $12.4-19.1$ \\
\hline \multicolumn{5}{|l|}{ Education } \\
\hline Primary school or less & $1248(37.8)$ & 306 & 22.4 & $19.7-25.3$ \\
\hline Secondary school & $1330(45.2)$ & 277 & 18.2 & $15.7-20.9$ \\
\hline University/college & $495(17.0)$ & 89 & 13.6 & $10.6-17.3$ \\
\hline \multicolumn{5}{|l|}{ Occupation } \\
\hline Senior officials and professionals & $260(8.7)$ & 39 & 14.8 & $10.3-20.7$ \\
\hline Elementary occupations & $1504(48.5)$ & 309 & 19.1 & $16.8-21.6$ \\
\hline Others & $1316(42.8)$ & 325 & 19.6 & $17.3-22.0$ \\
\hline \multicolumn{5}{|l|}{ Income } \\
\hline Lower income & $1493(46.4)$ & 328 & 19.3 & $17.1-21.9$ \\
\hline Middle income & $1055(35.5)$ & 225 & 17.6 & $14.9-20.6$ \\
\hline Higher income & $532(18.1)$ & 120 & 20.6 & $16.9-24.7$ \\
\hline \multicolumn{5}{|l|}{ BMI } \\
\hline $\mathrm{BMI}<25$ & $2523(84.4)$ & 469 & 16.0 & $14.4-17.7$ \\
\hline $\mathrm{BMI} \geq 25$ & $520(15.6)$ & 202 & 36.7 & $31.8-41.9$ \\
\hline \multicolumn{5}{|l|}{ Smoking status } \\
\hline Nonsmoker & $2354(74.5)$ & 493 & 17.9 & $16.3-19.7$ \\
\hline Smoker & $720(25.5)$ & 179 & 22.0 & $18.6-25.9$ \\
\hline \multicolumn{5}{|l|}{ Drinking status } \\
\hline Nondrinker & $1861(55.9)$ & 368 & 16.8 & $14.9-18.9$ \\
\hline Drinker & $1219(44.1)$ & 305 & 21.6 & $19.0-24.5$ \\
\hline
\end{tabular}

for each PSU and household. All the results presented reflect the survey design and survey weights. In order to account for sampling error, Taylor-linearized standard errors are used to estimate all 95\% confidence intervals reported in Tables 1 and 2. The Taylor-linearized standard errors were calculated in Stata using the svy procedure. The reported 95\% CI can be interpreted as the range in which $95 \%$ of proportions for a given variable would fall among all the possible samples drawn from the same population using the same design. For multiple regression model, the backward selection procedures were used to select a suitable set of independent variables, with the cutoff point to eliminate a variable being $p>0.2$. For multiple regression model fitness, the estat gof goodness of fit was used.

2.5. Ethical Considerations. The protocol of the STEPS survey was approved by the Institutional Review Board of Hanoi University of Public Health. All human subjects in the study were asked for their written informed consent before data were collected, and all had the right to withdraw from the study at any time.

\section{Results}

Of the 3,856 selected participants, 3,758 responded to the survey (response rate of 97.4\%) and participated in stage 1 of the survey. However, the number of study subjects who participated in the second and third stages of the survey was only 3,080 (response rate of 79.9\%). The general characteristics of those study participants who participated in stages 2 and 3 are described in Table 3.

Table 1 presents the prevalence of hypertension by some sociodemographic factors. Data showed that the prevalence of hypertension increased significantly with age $(5.4 \%, 17.3 \%$, and $40.2 \%$ among people aged $18-29,30-49$, and 50-69, respectively). Male population had higher prevalence of hypertension compared to female population ( $23.1 \%$ vs. $14.9 \%)$. The prevalence of hypertension also varied as a function of three NCD risk factors, smoking, high BMI, and drinking. Specifically, among population with BMI less than 25 , the prevalence of hypertension was $16.0 \%$ while among population with BMI greater than/equal to 25 , this figure was $36.7 \%$. About $22 \%$ people currently smoking and $21.6 \%$ people currently drinking were reported to have hypertension. 
TABLE 2: Proportions of hypertensive people who were aware of their hypertensive status, being treated with medications, and had their high blood pressure controlled, Vietnam 2015.

\begin{tabular}{|c|c|c|c|c|}
\hline & $\begin{array}{c}\text { Number of } \\
\text { people with raised } \\
\text { blood pressure }\end{array}$ & $\begin{array}{c}\text { Percentage aware of } \\
\text { hypertensive } \\
\text { status }(95 \% \mathrm{CI})\end{array}$ & $\begin{array}{l}\text { Percentage treated } \\
\text { with medications } \\
(95 \% \mathrm{CI})\end{array}$ & $\begin{array}{l}\text { Percentage having } \\
\text { blood pressure } \\
\text { controlled }^{1}(95 \% \mathrm{CI})\end{array}$ \\
\hline Overall & 673 & $43.1(39.4-46.8)$ & $24.9(21.0-29.3)$ & $9.7(7.0-12.4)$ \\
\hline \multicolumn{5}{|l|}{ Sex } \\
\hline Men & 365 & $35.8(30.1-42.0)$ & $20.5(15.9-25.9)$ & $7.5(4.7-10.4)$ \\
\hline Women & 308 & $47.1(40.7-53.6)$ & $31.4(25.7-37.8)$ & $13.0(8.3-17.6)$ \\
\hline \multicolumn{5}{|l|}{ Age group } \\
\hline $18-29$ & 47 & $18.3(5.7-45.2)$ & $12.8(4.0-34.1)$ & $8.9(0.0-21.1)$ \\
\hline $30-49$ & 196 & $33.8(27.4-40.8)$ & $15.3(10.7-21.4)$ & $3.8(0.9-6.7)$ \\
\hline $50-69$ & 430 & $49.4(44.2-54.7)$ & $34.4(29.4-39.8)$ & $14.4(10.4-18.3)$ \\
\hline \multicolumn{5}{|l|}{ Residence } \\
\hline Urban & 310 & $49.9(42.2-57.5)$ & $30.1(24.2-36.7)$ & $13.5(9.6-18.7)$ \\
\hline Rural & 362 & $35.4(30.5-40.8)$ & $22.2(17.3-28.1)$ & $7.8(5.0-11.9)$ \\
\hline \multicolumn{5}{|l|}{ Ethnicity } \\
\hline Kinh & 578 & $43.7(38.9-48.5)$ & $26.3(22.0-31.1)$ & $10.6(7.9-14.0)$ \\
\hline Others & 95 & $22.0(13.9-33.1)$ & $17.1(9.4-29.0)$ & $5.0(1.7-14.1)$ \\
\hline \multicolumn{5}{|l|}{ Education } \\
\hline $\begin{array}{l}\text { Primary school or } \\
\text { less }\end{array}$ & 306 & $39.6(33.7-45.9)$ & $26.6(20.7-33.5)$ & $10.4(6.9-15.3)$ \\
\hline Secondary school & 277 & $40.9(34.0-48.3)$ & $23.5(18.0-30.1)$ & $9.9(6.4-15.0)$ \\
\hline University/college & 89 & $41.2(29.9-53.6)$ & $23.8(15.4-34.7)$ & $6.6(2.9-14.3)$ \\
\hline \multicolumn{5}{|l|}{ Occupation } \\
\hline $\begin{array}{l}\text { Senior officials } \\
\text { and professionals }\end{array}$ & 39 & $46.4(28.5-65.2)$ & $28.6(14.1-49.4)$ & $8.3(3.3-19.6)$ \\
\hline Elementary occupations & 309 & $33.6(28.1-39.5)$ & $18.4(13.7-24.2)$ & $7.8(4.9-12.1)$ \\
\hline Others & 325 & $46.9(40.3-53.6)$ & $31.5(25.7-37.9)$ & $12.1(8.6-16.6)$ \\
\hline \multicolumn{5}{|l|}{ Income } \\
\hline Lower income & 328 & $32.7(26.9-39.0)$ & $19.7(15.0-25.3)$ & $7.8(5.0-11.9)$ \\
\hline Middle income & 225 & $48.8(40.6-57.1)$ & $26.7(21.0-33.4)$ & $9.4(6.3-13.9)$ \\
\hline Higher income & 120 & $44.4(35.2-53.8)$ & $34.2(24.9-44.9)$ & $15.0(8.7-24.7)$ \\
\hline \multicolumn{5}{|l|}{ BMI } \\
\hline $\mathrm{BMI}<25$ & 469 & $35.6(30.8-40.7)$ & $18.7(14.9-23.3)$ & $8.9(6.2-12.7)$ \\
\hline $\mathrm{BMI} \geq 25$ & 202 & $51.2(43.1-59.1)$ & $38.7(30.8-47.3)$ & $11.5(7.3-17.6)$ \\
\hline \multicolumn{5}{|l|}{ Smoking status } \\
\hline Nonsmoker & 493 & $42.8(37.8-47.9)$ & $27.8(23.3-32.9)$ & $11.4(8.4-15.3)$ \\
\hline Smoker & 179 & $34.5(26.7-43.3)$ & $17.8(12.2-25.2)$ & $5.8(3.1-10.6)$ \\
\hline \multicolumn{5}{|l|}{ Drinking status } \\
\hline Nondrinker & 368 & $45.3(39.1-51.6)$ & $29.6(24.4-35.4)$ & $13.0(9.6-17.4)$ \\
\hline Drinker & 305 & $35.3(29.0-42.2)$ & $20.0(15.2-25.9)$ & $6.4(3.8-10.6)$ \\
\hline
\end{tabular}

${ }^{1}$ Percentage among the hypertensive people.

Table 2 provides a situational analysis about the level of awareness, treatment, and control of hypertension among people detected with hypertension in this survey. The prevalence of awareness was the percentage of people detected with hypertension in this survey who were aware of their condition; the prevalence of treated with medication was the percentage of people detected with hypertension in this survey who reported the current use of antihypertensive medications; the percentage of blood pressure controlled was the percentage of people detected with hypertension in this survey, who are currently on medication for raised blood pressure and have a blood pressure below 140/90 mmHg. There was a pattern of lower level of awareness, on medication and having blood pressure controlled among men compared to women $(35.8 \%, 20.5 \%$, and $7.5 \%$ vs. $47.1 \%$, $31.4 \%$, and $13.0 \%$, respectively); among rural area compared with urban areas $(35.4 \%, 22.2 \%$, and $7.8 \%$ vs. $49.9 \%, 30.1 \%$, and $13.5 \%$, respectively); among smokers compared with nonsmokers $(34.5 \%, 17.8 \%$, and $5.8 \%$ vs. $42.8 \%, 27.8 \%$, and $11.4 \%$, respectively); among drinkers compared with nondrinkers $(35.3 \%, 20.0 \%$, and $6.4 \%$ vs. $45.3 \%, 29.6 \%$, and $13.0 \%$, respectively); and among low-income compared with higher income $(32.7 \%, 19.7 \%$, and $7.8 \%$ vs. $44.4 \%, 34.2 \%$, and $15.0 \%$, respectively).

Multivariate logistic regression models were applied to examine the association between multiple behavioral and socioeconomic factors with raised blood pressure and awareness of high blood pressure. For the model of raised blood pressure, all variables were used in the model and the goodness of fit test showed good fit for the model. For the awareness of raised blood pressure model, the income variable was omitted to satisfy the requirement for the good of fitness test (the inclusion of this variable cause the model to fail the goodness of fit test). 
TABLE 3: General characteristics of the study respondents, STEPS Vietnam 2015.

\begin{tabular}{|c|c|c|}
\hline & $\begin{array}{c}\text { Sample size and } \\
\text { unweighted } \\
\text { percentage, } n\end{array}$ & $\begin{array}{l}\text { Weighted } \\
\text { percentage }\end{array}$ \\
\hline \multicolumn{3}{|l|}{ Gender } \\
\hline Men & $1320(42.9)$ & 49.5 \\
\hline Women & $1760(57.1)$ & 50.5 \\
\hline \multicolumn{3}{|l|}{ Age group } \\
\hline $18-29$ & $489(15.9)$ & 32.4 \\
\hline $30-49$ & $1500(48.7)$ & 43.6 \\
\hline $50-69$ & $1091(35.4)$ & 24.0 \\
\hline \multicolumn{3}{|l|}{ Residence } \\
\hline Urban & $1380(44.8)$ & 34.9 \\
\hline Rural & $1700(55.2)$ & 65.1 \\
\hline \multicolumn{3}{|l|}{ Ethnicity } \\
\hline Kinh & $2514(81.6)$ & 80.2 \\
\hline Others & $566(18.4)$ & 19.8 \\
\hline \multicolumn{3}{|l|}{ Education } \\
\hline Primary school or less & $1248(40.5)$ & 37.8 \\
\hline Secondary school & $1330(43.2)$ & 45.2 \\
\hline University/college & $495(16.1)$ & 17.0 \\
\hline \multicolumn{3}{|l|}{ Occupation } \\
\hline Senior officials and professionals & $260(8.4)$ & 8.7 \\
\hline Elementary occupations & $1504(48.8)$ & 48.5 \\
\hline Others & $1316(42.7)$ & 42.8 \\
\hline \multicolumn{3}{|l|}{ Income level } \\
\hline Lower income & $1493(48.5)$ & 46.4 \\
\hline Middle income & $1055(34.3)$ & 35.5 \\
\hline Higher income & $532(17.3)$ & 18.1 \\
\hline \multicolumn{3}{|l|}{ BMI } \\
\hline $\mathrm{BMI}<25$ & 2523 (81.9) & 84.4 \\
\hline $\mathrm{BMI} \geq 25$ & $520(16.9)$ & 15.6 \\
\hline \multicolumn{3}{|l|}{ Smoking status } \\
\hline Nonsmoker & $2354(76.4)$ & 74.5 \\
\hline Smoker & $720(23.4)$ & 25.5 \\
\hline \multicolumn{3}{|l|}{ Drinking status } \\
\hline Nondrinker & $1861(60.4)$ & 55.9 \\
\hline Drinker & $1219(39.6)$ & 44.1 \\
\hline \multicolumn{3}{|l|}{ Diabetes status } \\
\hline Diabetes & $155(5.0)$ & 4.1 \\
\hline Nondiabetes & $2925(95.0)$ & 95.9 \\
\hline Total & $3080(100)$ & \\
\hline
\end{tabular}

As shown in Table 4, age was a statistically significant correlate of raised blood pressure. The prevalence increased with age and was statistically different among people aged 30-49 (OR $=3.54,95 \% \mathrm{CI}: 2.19-5.71)$ and 50-69 years old $(\mathrm{OR}=11.36,95 \% \mathrm{CI}: 7.06-18.26)$ as compared to the $18-29$ group. Males were associated with higher raised blood pressure $(\mathrm{OR}=2.35,95 \% \mathrm{CI}: 1.77-3.14)$ compared to females. Similarly, overweight/obesity and people with diabetes status were shown to be statistically significant predictors of raised blood pressure with $\mathrm{OR}=2.80$ (95\% CI: 2.12-3.69) and OR=2.13 (95\% CI: 1.51-3.55), respectively. There was no statistically significant difference in prevalence of raised blood pressure by economic condition of household and smoking status.

As for awareness of raised blood pressure, Table 4 shows that older age $(\mathrm{OR}=4.20,95 \% \mathrm{CI}: 1.27-13.81$ (age $50-69$ vs. age $18-29)$, overweight $(\mathrm{OR}=1.79,95 \% \mathrm{CI}: 1.16-2.75)$, vs. non-overweight were associated with higher awareness of raised blood pressure. On the other hand, being ethnic minority $(\mathrm{OR}=0.54,95 \% \mathrm{CI}: 0.30-0.97)$ was associated with lower level of awareness of raised blood pressure.

\section{Discussion}

The prevalence and associated factors of raised blood pressure and raised blood pressure management are of interest for health staffs, planners, and policy makers in Vietnam as well as in other similar settings in the world. The STEPS survey, which was conducted in 2015 with a national representative sample, showed that the overall prevalence of raised blood pressure in adults aged 18 to 69 was $18.9 \%$. This indicates that the condition already affects a sizeable proportion of the adult population in Vietnam. The prevalence estimated in this study could not be compared with the previous surveys in Vietnam due to differences in sampling methods, age groups, and geographical coverage.

The prevalence of raised blood pressure in the present study is lower than the prevalence of raised blood pressure in selected countries and regions such as Africa (30.8\% in 2010) [11], China (from $20.5 \%$ to $28.7 \%$ ) [12-16], Labanon (29.3\%) [17], and Turkey (24.8\%) [18]. Compared with the results from the systematic review and meta-analysis in 2015 comprising data on 45 low- and middle-income countries, which reported the pooled raised blood pressure prevalence of $37.8 \%$ (95\% CI: 35.0-40.6) in upper middle-income countries and 23.1\% (95\% CI: 20.1-26.2) in low-income countries, the prevalence in Vietnam is also much lower [19]. In contrast, the prevalence of raised blood pressure in a Tanzania community-based on a cross-sectional study in 2013 was $8.0 \%$ [20], which is much lower than in our study.

The difference in raised blood pressure in men and women $(23.09 \%$ vs. $14.86 \%)$ in Vietnam found in this study was consistent with the findings from previous Vietnamese studies $[5,7,8,21]$. This pattern was also comparable to other studies carried out in both developed and developing countries $[3,12,14-18,22]$. In contrast to other studies, a meta-analysis of 45 countries found that there was no significant sex-difference in raised blood pressure prevalence [19]. A key predictor of blood pressure in many populations is age, and the present study found similar results to other international and Vietnamese studies [5, 7, 8, 12-15, 19-23] confirming age to be positively correlated with raised blood pressure. Our results correspond to previous research which found that people who are overweight $[7,11-13,17,19,20]$, are smokers [22-24], and have diabetes [12, 13, 20, 25] were shown to have a higher risk for raised blood pressure.

In terms of socioeconomic correlates of raised blood pressure, there was no statistically significant difference in prevalence of raised blood pressure by occupational status, ethnicity, and economic condition of household, residency, and drinking status but showed that raised blood pressure was found to be associated with education level. Previous studies show inconsistent results related to these factors $[13,19,20,22,23,26]$.

This study also revealed that the rates of awareness, treatment, and control of high blood pressure in the study 
TABLE 4: Multiple regression analyses: association between sociodemographic factors and hypertension and awareness of hypertension status in Vietnam, 2015.

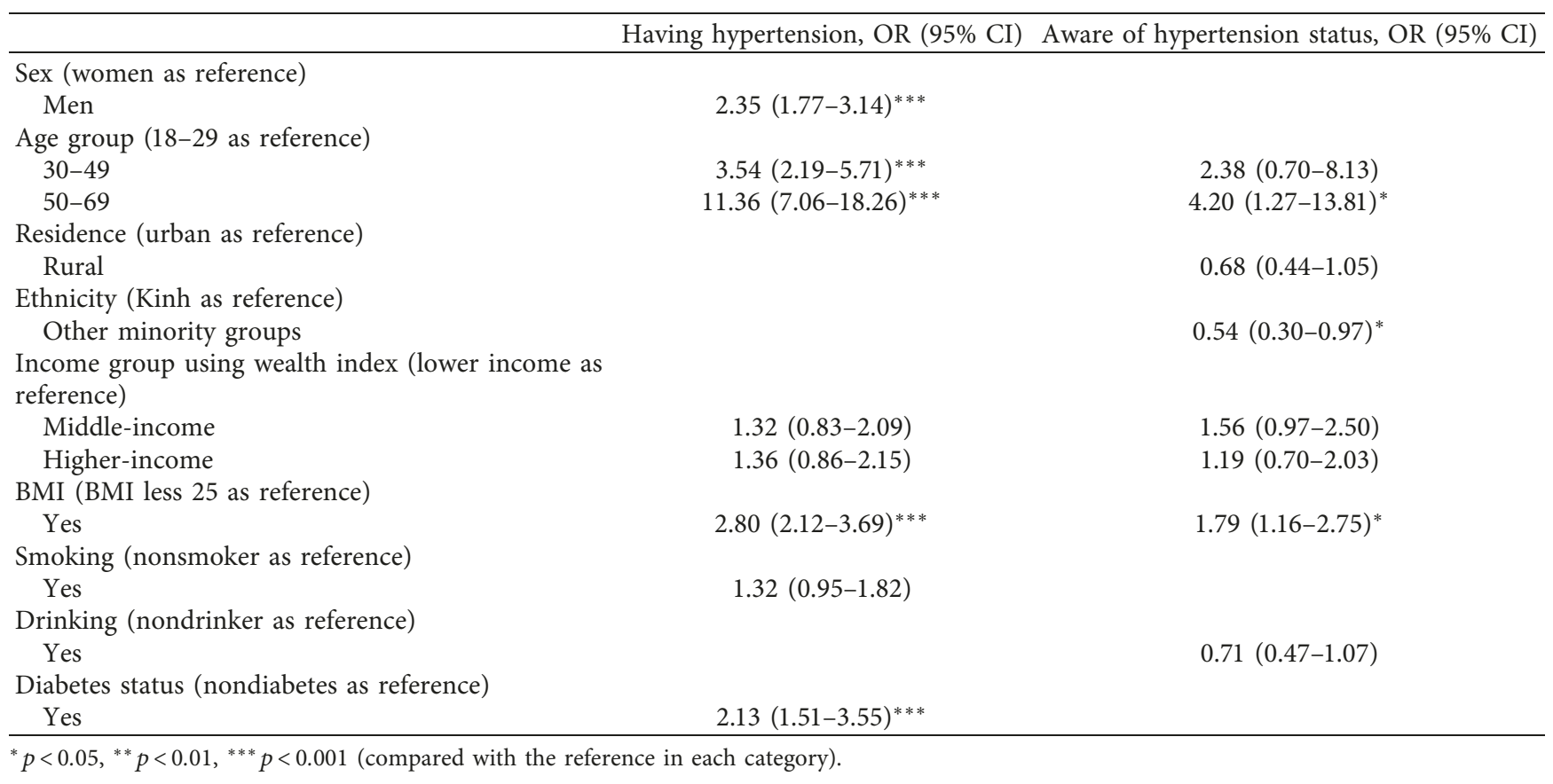

populations were low $(43.1 \%, 24.9 \%$, and $9.7 \%$, respectively). This fact was also reported by other studies conducted in Vietnam [5, 7, 8, 21], India in 2003 [27], Bangladesh in 2004 [28], Thailand in 2006 [29], and China [13, 15, 30]. These results underscore the urgent need for developing strategies and measures for improving awareness, prevention, and control of high blood pressure in Vietnam and other countries with similar problems.

This study's result is consistent with the findings that potential factors associated with awareness were age [14, 23] and overweight/obese $[12,15]$. Other important predictors of awareness are living area and being ethnic minority consistent with other studies [7, 12, 15, 23, 26]. However, this study has not confirmed previous research that sex is also a factor associated with awareness of raised blood pressure [7, 12, 23].

In summary, our findings showed that raised blood pressure in Vietnam is a serious problem both because of its magnitude and the unacceptably high unawareness rate in the population. Given the findings from this study, public health actions dealing with the problems of raised blood pressure (such as health education, early detection and management of cases in primary care level, etc.) are urgent, while taking into account its relationship with age and socioeconomic status. It is clear that the interventions should address all people in society, with a focus on disadvantaged groups such as ethnic groups and rural population. This study was just a starting point. Deeper and more sophisticated analyses are needed to understand the situation in more detail. Nonetheless, the simple but valuable information emerging from this study will certainly help in planning and policy-making processes.

\section{Data Availability}

The data used to support the findings of this study are available from the corresponding author upon request.

\section{Disclosure}

The funding source has no role in the interpretation of data and in writing the manuscript.

\section{Conflicts of Interest}

The authors declare that there are no conflicts of interest regarding the publication of this study.

\section{Acknowledgments}

This article made use of the dataset of the STEPS survey which is supported by the World Health Organization. The study was funded by the World Health Organization. The funding source provided financial and logistics support during data collection.

\section{References}

[1] S. S. Lim, T. Vos, A. D. Flaxman et al., "A comparative risk assessment of burden of disease and injury attributable to 67 risk factors and risk factor clusters in 21 regions, 1990-2010: a systematic analysis for the Global Burden of Disease Study 2010," Lancet, vol. 380, no. 9859, pp. 2224-2260, 2012.

[2] World Health Organization, Global Status Report on Noncommunicable Diseases 2010, World Health Organization, Geneva, Switzerland, 2010. 
[3] World Health Organization, Global Status Report on Noncommunicalbe Diseases 2014, World Health Organization, Geneva, Switzerland, 2014.

[4] World Health Organization, A Global Brief on Hypertension: Silent Killer, Global Public Health Crisis, World Health Organization, Geneva, Switzerland, 2013.

[5] Ministry of Health of Vietnam, Vietnam National Health Survey 2001-2002, Ministry of Health Vietnam, Hanoi, Vietnam, 2003.

[6] N. C. Khan and H. H. Khoi, "Double burden of malnutrition: the Vietnamese perspective," Asia Pacific Journal of Clinical Nutrition, vol. 17, no. 1, pp. 116-118, 2008.

[7] P. T. Son, N. N. Quang, N. L. Viet et al., "Prevalence, awareness, treatment and control of hypertension in Vietnam-results from a national survey," Journal of Human Hypertension, vol. 26, no. 4, pp. 268-280, 2012.

[8] Ministry of Health of Vietnam, The STEPS Survey of Chronic Disease Risk Factors in Viet Nam, Ministry of Health Vietnam, Hanoi, Vietnam, 2010.

[9] World Health Organization, STEPwise Approach to Noncommunicable Disease Risk Factor Surveillance (STEPS), World Health Organization, Geneva, Switzerland, 2015, http://www.who.int/chp/steps/riskfactor/en/.

[10] S. Vyas and L. Kumaranayake, "Constructing socio-economic status indices: how to use principal components analysis," Health Policy and Planning, vol. 21, no. 6, pp. 459-468, 2006.

[11] J. Kayima, R. K. Wanyenze, A. Katamba, E. Leontsini, and F. Nuwaha, "Hypertension awareness, treatment and control in Africa: a systematic review," BMC Cardiovascular Disorders, vol. 13, no. 1, 2013.

[12] H. Wang, X. Zhang, J. Zhang et al., "Factors associated with prevalence, awareness, treatment and control of hypertension among adults in Southern China: a community-based, crosssectional survey," PLoS One, vol. 8, no. 5, Article ID e62469, 2013.

[13] X. Liu, W. Gu, Z. Li, H. Lei, G. Li, and W. Huang, "Hypertension prevalence, awareness, treatment, control, and associated factors in Southwest China," Journal of Hypertension, vol. 35, no. 3, pp. 637-644, 2017.

[14] L. Yang, J. Yan, X. Tang, X. Xu, W. Yu, and H. Wu, "Prevalence, awareness, treatment, control and risk factors associated with hypertension among adults in Southern China, 2013," PLoS One, vol. 11, no. 1, Article ID e0146181, 2016.

[15] M. Hu, Y. Wan, L. Yu et al., "Prevalence, awareness, treatment, and control of hypertension and associated risk factors among adults in Xi'an, China: a cross-sectional study," Medicine (Baltimore), vol. 95, no. 34, e4709 pages, 2016.

[16] S. Tian, G.-H. Dong, D. Wang et al., "Factors associated with prevalence, awareness, treatment and control of hypertension in urban adults from 33 communities in China: the CHPSNE Study," Hypertension Research, vol. 34, no. 10, pp. 1087-1092, 2011.

[17] B. B. Mouhtadi, R. M. N. Kanaan, M. Iskandarani, M. K. Rahal, and D. H. Halat, "Prevalence, awareness, treatment, control and risk factors associated with hypertension in Lebanese adults: a cross sectional study," Global Cardiology Science and Practice, vol. 2018, 2018.

[18] I. Dastan, A. Erem, and V. Cetinkaya, "Awareness, treatment, control of hypertension, and associated factors: results from a Turkish national study," Clinical and Experimental Hypertension, vol. 40, no. 1, pp. 90-98, 2018.

[19] A. M. Sarki, C. U. Nduka, S. Stranges, N. B. Kandala, and O. A. Uthman, "Prevalence of hypertension in low- and middle-income countries: a systematic review and meta- analysis," Medicine (Baltimore), vol. 94, no. 50, e1959 pages, 2015.

[20] N. R. Mosha, M. Mahande, A. Juma et al., "Prevalence, awareness and factors associated with hypertension in North West Tanzania," Global Health Action, vol. 10, no. 1, Article ID 1321279, 2017.

[21] National Heart Institute of Vietnam, Survey on Noncommunicable Diseases Risk Factors in Vietnam, National Heart Institute of Vietnam, Hanoi, Vietnam, 2002.

[22] J. Guo, Y.-C. Zhu, Y.-P. Chen, Y. Hu, X.-W. Tang, and B. Zhang, "The dynamics of hypertension prevalence, awareness, treatment, control and associated factors in Chinese adults," Journal of Hypertension, vol. 33, no. 8, pp. 1688-1696, 2015.

[23] H. T. P. Do, J. M. Geleijnse, M. B. Le, F. J. Kok, and E. J. M. Feskens, "National prevalence and associated risk factors of hypertension and prehypertension among Vietnamese adults," American Journal of Hypertension, vol. 28, no. 1, pp. 89-97, 2015.

[24] M. K. Khanal, R. R. Dhungana, P. Bhandari, Y. Gurung, and K. N. Paudel, "Prevalence, associated factors, awareness, treatment, and control of hypertension: findings from a cross sectional study conducted as a part of a community based intervention trial in Surkhet, Mid-western region of Nepal," PLoS One, vol. 12, no. 10, Article ID e0185806, 2017.

[25] B. Doulougou, F. Gomez, B. Alvarado et al., "Factors associated with hypertension prevalence, awareness, treatment and control among participants in the International Mobility in Aging Study (IMIAS)," Journal of Human Hypertension, vol. 30, no. 2, pp. 112-119, 2016.

[26] W. J. Ma, J. L. Tang, Y. H. Zhang et al., "Hypertension prevalence, awareness, treatment, control, and associated factors in adults in Southern China," American Journal of Hypertension, vol. 25, no. 5, pp. 590-596, 2012.

[27] N. Bharucha and T. Kuruvilla, "Hypertension in the Parsi community of Bombay: a study on prevalence, awareness and compliance to treatment," BMC Public Health, vol. 3, no. 1, 2003.

[28] M. A. Sayeed, H. Mahtab, P. A. Khanam, R. Begum, A. Banu, and A. K. Azad Khan, "Diabetes and hypertension in pregnancy in a rural community of Bangladesh: a populationbased study," Diabetic Medicine, vol. 22, no. 9, pp. 1267-1271, 2005.

[29] Ministry of Public Health of Thailand, The Report of Thailand Population Health Examination Survey III, 2003-2004, Ministry of Public Health, Bangkok, Thailand, 2006.

[30] J. Zhang, Q. Huang, M. Yu et al., "Prevalence, awareness, medication, control, and risk factors associated with hypertension in Bai ethnic group in rural China: the Yunnan minority eye study," PLoS One, vol. 8, no. 8, Article ID e70886, 2013. 


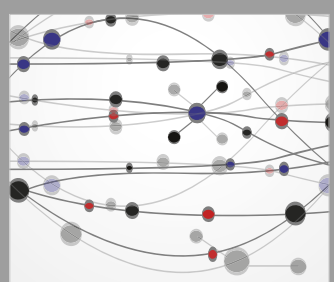

The Scientific World Journal
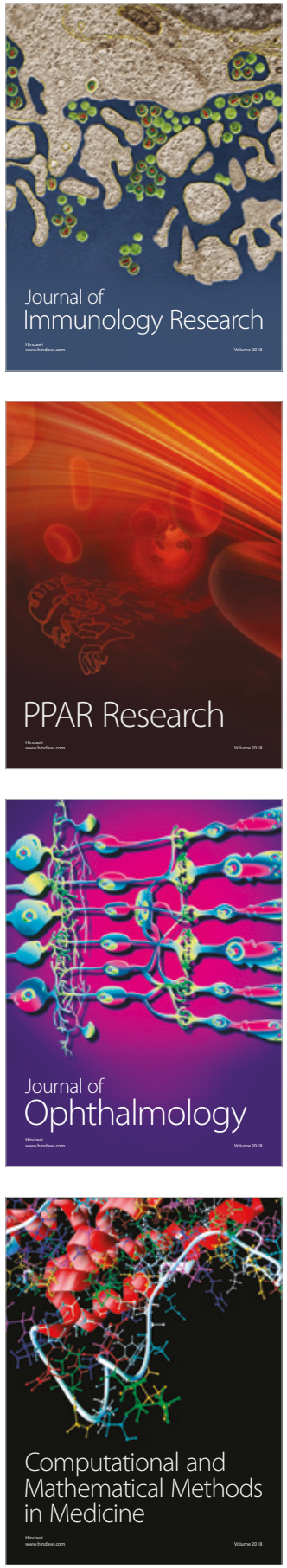

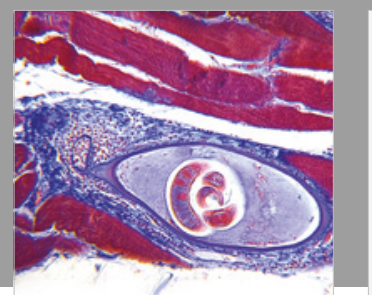

Gastroenterology Research and Practice

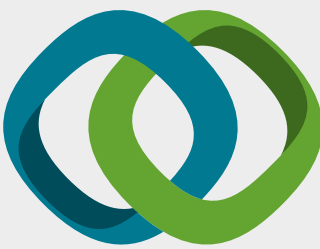

\section{Hindawi}

Submit your manuscripts at

www.hindawi.com
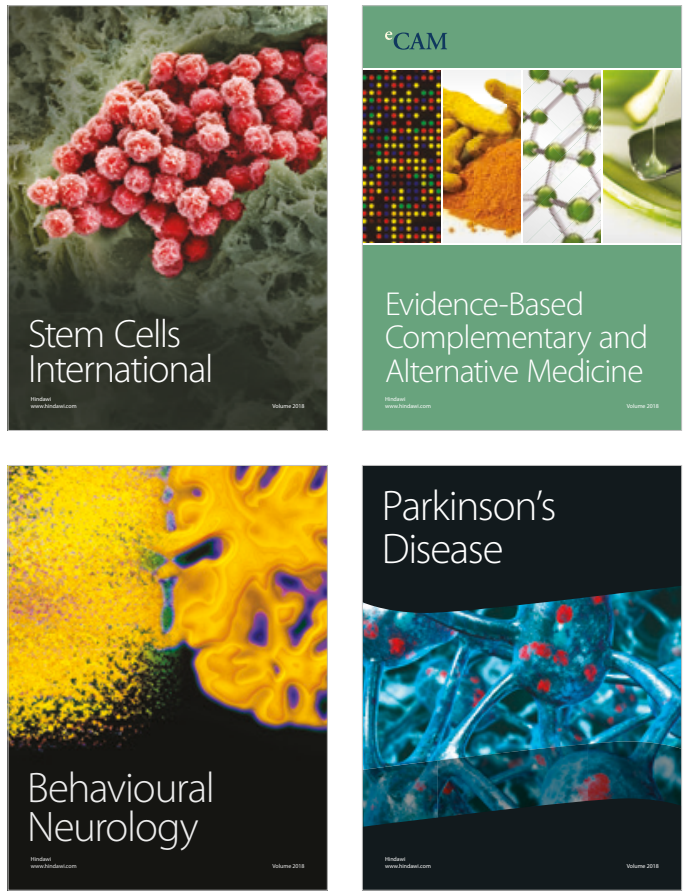

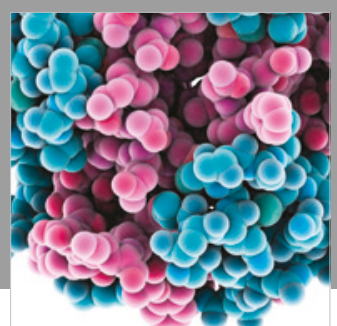

ournal of

Diabetes Research

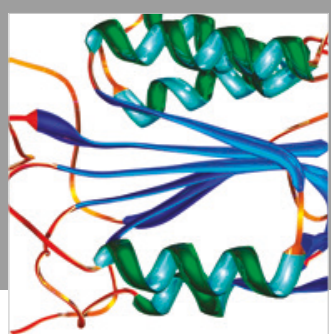

Disease Markers
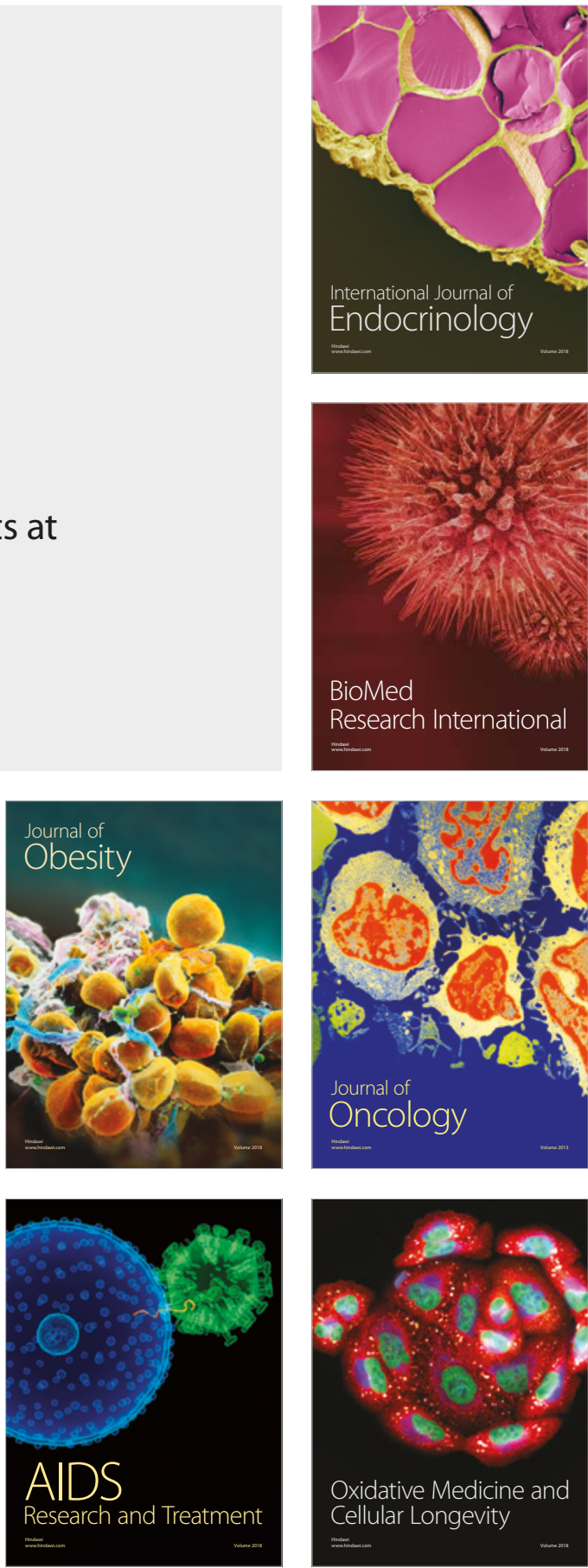